Check for updates

Cite this: RSC Adv., 2017, 7, 37340

Received 16th June 2017

Accepted 17th July 2017

DOI: $10.1039 / c 7 r a 06735 f$

rsc.li/rsc-advances

\section{Rapid screening of photoactivatable metallodrugs: photonic crystal fibre microflow reactor coupled to ESI mass spectrometry $\dagger$}

\author{
Ruth J. McQuitty, (D) a Sarah Unterkofler, (D) ${ }^{b}$ Tijmen G. Euser, (D) bc \\ Philip St.J. Russell (D) *b and Peter J. Sadler (iD *a
}

\begin{abstract}
We explore the efficacy of a hyphenated photonic crystal fibre microflow reactor - high-resolution mass spectrometer system as a method for screening the activity of potential new photoactivatable drugs. The use of light to activate drugs is an area of current development as it offers the possibility of reduced side effects due to improved spatial and temporal targeting and novel mechanisms of anticancer activity. The di-nuclear ruthenium complex $\left[\left\{\left(\eta^{6} \text {-indan) } \mathrm{RuCl}\right\}_{2}(\mu-2,3-\mathrm{dpp})\right]\left(\mathrm{PF}_{6}\right)_{2}\right.$, previously studied by Magennis et al. (Inorg. Chem., 2007, 46, 5059) is used as a model drug to compare the system to standard irradiation techniques. The photodecomposition pathways using blue light radiation are the same for PCF and conventional cuvette methods. Reactions in the presence of small biomolecules $5^{\prime}$-guanosine monophosphate (5'-GMP), 5'-adenosine monophosphate (5'-AMP), L-cysteine (L-Cys) and glutathione ( $\gamma$-L-glutamyl-L-cysteinyl-glycine, GSH) were studied. The complex was found to bind to nucleobases in the dark and this binding increased upon irradiation with $488 \mathrm{~nm}$ light, forming the adducts [ $\eta^{6}$-indan) $\left.\mathrm{Ru}_{2}(\mu-2,3-\mathrm{dpp})+5^{\prime}-\mathrm{GMP}\right]^{2+}$ and $\left[\left(\eta^{6} \text {-indan) } \mathrm{Ru}+\left(5^{\prime}-\mathrm{AMP}\right)\right]^{+}\right.$. These findings are consistent with studies using conventional methods. The dinuclear complex also binds strongly to GSH after irradiation, a possible explanation for its lack of potency in cell line testing. The use of the PCF-MS system dramatically reduced the sample volume required and reduced the irradiation time by four orders of magnitude from 14 hours to 12 seconds. However, the reduced sample volume also results in a reduced MS signal intensity. The dead time of the combined system is $15 \mathrm{~min}$, limited by the intrinsic dead volume of the HR-MS.
\end{abstract}

\section{Introduction}

The use of light activated drugs in the form of photodynamic therapy (PDT) is well established in the clinic, having gained FDA approval in the US in $1995 .{ }^{1}$ Photodynamic therapy involves the use of a photosensitiser that is irradiated with light, normally within the 'phototherapeutic window' of 650-850 $\mathrm{nm}$. The excited photosensitiser then generates reactive oxygen species, especially ${ }^{1} \mathrm{O}_{2}$, which cause irreparable damage to the tumour cell and induce cell death. ${ }^{2}$ Although a proven treatment, PDT does have its limitations, such as photosensitivity of the patient after treatment and the reliance of the treatment on

${ }^{a}$ Department of Chemistry, University of Warwick, Gibbet Hill Road, Coventry CV7 4AL, UK. E-mail: P.J.Sadler@warwick.ac.uk

${ }^{b}$ Max-Planck Institute for the Science of Light, Staudtstrasse 2, D-91058 Erlangen, Germany.E-mail: Philip.Russell@mpl.mpg.de

${ }^{c}$ NanoPhotonics Group, Cavendish Laboratory, JJ Thomson Avenue, Cambridge CB3 OHE, UK

$\dagger$ Electronic supplementary information (ESI) available. See DOI: $10.1039 / \mathrm{c} 7 \mathrm{ra06735f}$ the presence of oxygen, which means that its efficacy is curbed in the hypoxic regions of solid tumours. ${ }^{3}$

The search for improved photoactive drugs with a wider spectrum of activity and that possess a mechanism of action independent of the presence of oxygen has led to many new photoactive agents being synthesised. Some of these make use of the unique photochemistry of inorganic compounds, utilising a range of metal centres such as iridium, ${ }^{4}$ ruthenium, ${ }^{5}$ platinum, ${ }^{6}$ and dinuclear mixed-metal complexes. ${ }^{7-10}$ Examples from our own work include photoactivatable diazido Pt(Iv) complexes, ${ }^{11}$ and organometallic $\mathrm{Ru}(\mathrm{II})$ compounds. ${ }^{12,13}$ This work has resulted in promising drug candidates, such as trans, trans, trans-[Pt $\left.(\mathrm{py})_{2}\left(\mathrm{~N}_{3}\right)_{2}(\mathrm{OH})_{2}\right]$ which is active at micromolar concentrations against a range of cancer cell lines when irradiated with low doses of blue light. ${ }^{14}$

Since the chemistry of electronically-excited states of photoactive metal complexes differs from that of the ground state, photoproducts are likely to be produced which can affect cellular biochemical pathways in novel ways. ${ }^{15}$ Such behaviour may be advantageous for avoiding cross-resistance with existing drugs. For example, combatting resistance to current platinum drugs is an important clinical problem. ${ }^{16}$ Hence there is a need 
to devise methods for analysis of the photodecomposition pathways of photochemotherapeutic agents on a wide range of timescales. Conventional methods often involve the separate irradiation and subsequent analysis of a photoactive compound in solution, require relatively high sample volumes (at least 600 $\mu \mathrm{L}$ ), and can involve lengthy sample handling procedures. The aim of the current work is to utilise the unique properties of liquid-filled hollow-core photonic crystal fibres (HC-PCFs) to act as micro flow-reactors for the efficient activation and analysis of photoactivatable drugs on a much shorter timescale than is possible with conventional methods.

HC-PCFs are fibres constructed from silica, comprising a $\sim 20 \mu$ m-sized hollow core channel, surrounded by a regular two-dimensional arrangement of smaller channels (total diameter $c a .200 \mu \mathrm{m}),{ }^{17}$ see Fig. 1B. The HC-PCF design, such as the core size, the cladding pitch, and the thickness of the glass webs surrounding the hollow core, can be adjusted such that a desired range of wavelengths is guided along the core with negligible losses. ${ }^{18-20}$ The same guiding mechanism, though over a shifted wavelength range, applies when the microstructure is filled with a liquid, ${ }^{21,22}$ meaning that light can propagate in well-defined optical modes along a microscale microfluidic channel, as shown in Fig. 1B.

Such optofluidic HC-PCFs are outstanding photochemical microreactors, that outperform on-chip optofluidic waveguides $^{23,24}$ in several ways. ${ }^{25,26}$ First of all, the reaction volume per $\mathrm{cm}$ interaction length is reduced to a few $\mathrm{nL} \mathrm{cm}{ }^{-1}$ enabling studies on minute sample volumes. In terms of photochemistry, the available optical power $P$ is confined to the small crosssectional area of the core $\left(A_{\text {core }} \sim 300 \times 10^{-12} \mathrm{~m}^{2}\right)$, resulting in a five orders of magnitude larger average irradiance $(I=P /$
$\left.A_{\text {core }}\right)$, as compared to a standard size cuvette irradiated by a free-space beam. As a result, much lower laser powers are required to achieve the same excitation conditions. Finally, HCPCF allows long optical path lengths that can be exploited for enhanced detection sensitivity. Additional advantages are that HC-PCFs are easily fabricated by established procedures ${ }^{27}$ from high-quality fused silica glass, featuring negligible scattering and absorbance in the UV-Vis range, as well as chemical inertness.

Recent experimental studies have proven the efficacy of optofluidic PCFs as efficient photochemical reactors. Using simultaneous in-fibre absorption spectroscopy on a fixed, static sample volume, efficient photoconversion of low quantum yield reactions, ${ }^{25}$ photo-induced homogeneous catalysis, ${ }^{28}$ and monitoring of the reaction kinetics of photoswitchable dyes with sub-picomole sensitivity have been successfully demonstrated..$^{29}$ Cubillas et al. have published a comprehensive review of the uses of PCFs for photochemistry and sensing applications. $^{30}$

The analysis of photodecomposition pathways in HC-PCFs usually relies on absorption spectroscopy within the fibre core. While providing some useful in situ information, an important limitation is that it is very difficult to deduce structural information of reaction products from the absorption spectrum alone. For this reason, we have recently combined a continuous-flow HC-PCF microreactor with non-optical analysis methods to characterise unknown species more fully. A piece of optofluidic HC-PCF was interfaced with a low-volume microfluidic circuit, enabling photochemical reaction products to be fed directly into a mass spectrometer (MS), ${ }^{31}$ see Fig. 1D. As a proof-of-principle, the well-known photoaquation
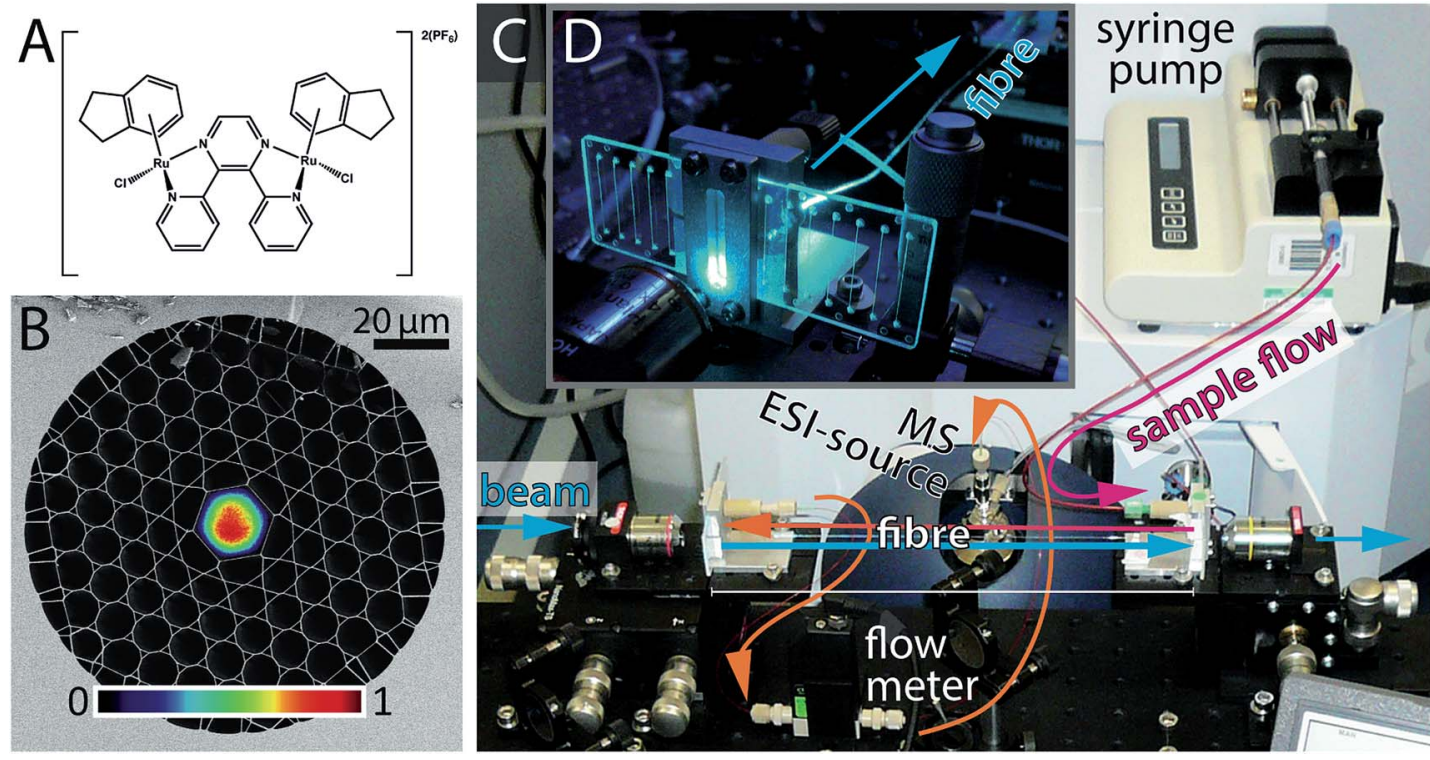

Fig. 1 (A) Structure of $1,\left[\left\{\left(\eta^{6} \text {-indan)RuCl }\right\}_{2}(\mu-2,3-d p p)\right]\left(\mathrm{PF}_{6}\right)_{2}\right.$. (B) Scanning electron micrograph of the kagomé-lattice HC-PCF. Grey areas correspond to fused silica glass and black areas correspond to holes, which in our experiment are filled with sample solution. The overlayed image is the optical mode at $488 \mathrm{~nm}$ wavelength, measured by a CCD camera. (C) Photograph of the experimental setup. Custom-made optofluidic interface mounts (see D) are used to couple light into the optofluidic PCF flow reactor. (D) Photograph of one optofluidic interface mount, accommodating an off-the-shelf straight-channel optofluidic chip. 
reaction of cyanocobalamin (vitamin $\mathrm{B}_{12}$ ) to aquacobalamin was studied and found to be in excellent agreement with conventional irradiation methods. ${ }^{32}$ Importantly, the amount of sample required was reduced 50 times when compared to the conventional batch procedure using a cuvette.

In this study, we apply this novel optofluidic system to gain new insight into the properties of potential photoactivatable drugs. The ruthenium complex 1, shown in Fig. 1A, is a dinuclear complex previously studied by Magennis et al. ${ }^{33}$ Upon irradiation, 1 was found to lose an indane ligand and bind to DNA. The complex can also undergo aquation in aqueous solution in the dark, resulting in the loss of the chlorido ligands. We have studied he photoactivation of $\mathbf{1}$ in the presence of a range of biomolecules as a guide to its possible intracellular behaviour.

\section{Experimental section}

Materials

All water used was doubly deionised water (DDW), purified using a Multipore Milli Q and a USF Elga UHQ water deionisers. Microfluidic mounts were constructed in-house at the Max Planck Institute for the Science of Light in Erlangen. The microfluidic chips were purchased from microfluidic ChipShop. For sample introduction, a $500 \mu \mathrm{L}$-glass syringe from Hamilton was used and a syringe pump from kdScientific. Sodium salt 5'-GMP (99.99\%) and L-cysteine (99.99\%) were purchased from Sigma Aldrich. Both the 5'-AMP (99.99\%) and glutathione (GSH, 99.99\%) were purchased from Acros Organics. Complex $1\left(\left[\left\{\left(\eta^{6}\right.\right.\right.\right.$-indan $\left.\left.) \mathrm{RuCl}_{2}(\mu-2,3-\mathrm{dpp})\right]\left(\mathrm{PF}_{6}\right)_{2}\right)$ was synthesised according to the literature method. ${ }^{33}$

\section{Sample preparation}

All MS samples were filtered using NALGENE $0.2 \mu \mathrm{m}$ PES filters and then centrifuged at $14000 \mathrm{rpm}, 5{ }^{\circ} \mathrm{C}$ for $10 \mathrm{~min}$. The $\mathrm{pH}$ of samples was measured using a Mettler-Toledo glass microelectrode connected to a Martini instruments Mi150 pH/ temperature bench meter calibrated at $\mathrm{pH} 4,7$ and 10 using pH buffers from Mettler-Toledo.

\section{Mass spectrometry}

All mass spectra were obtained on a Bruker MaXis highresolution mass spectrometer (HR-MS). Samples were introduced to the MS at a flow rate of $100 \mu \mathrm{L} \mathrm{h}{ }^{-1}$. The acquisition parameters for spectra obtained in the positive mode were as follows: scan range $50-3000 \mathrm{~m} / \mathrm{z}$, set capillary $3000 \mathrm{~V}$, end plate off-set $-500 \mathrm{~V}$, nebuliser pressure 0.4 bar, dry heater $180{ }^{\circ} \mathrm{C}$, and dry gas $4.0 \mathrm{~L} \mathrm{~min}^{-1}$. All spectra were processed using Bruker Daltonics Analysis software and Origin Pro 8.1.

\section{Optofluidic setup}

A photograph of the optofluidic photochemical microflow reactor is shown in Fig. 1C and D. Details of the implementation, especially of the optofluidic interface between the optical fibre facets and the microfluidic circuitry (PEEK tubing equipment by VICI and Upchurch Scientific) via off-the-shelf microfluidic chips (microfluidic Chipshop), can be found in Unterkofler et al. ${ }^{31}$ The HC-PCF used in the experiments was a $L$ $\approx 15 \mathrm{~cm}$ long kagomé-type HC-PCF ${ }^{20}$ with a core diameter of $19.7 \mu \mathrm{m}$ (Fig. 1A). This corresponds to a fibre-dead volume of $\sim 1.4 \mu \mathrm{L}$ in the cladding holes and $\sim 50 \mathrm{~nL}$ in the optofluidic core. The fibre guides blue light (488 nm) in a well-defined optical mode (see Fig. 1B) with waveguide loss of $3.5 \mathrm{~dB} \mathrm{~m}^{-1}$, meaning that the transmission losses through the $15 \mathrm{~cm}$ long fibre are below $12 \%$. The inner diameter $(100 \mu \mathrm{m})$ and length $(60 \mathrm{~cm})$ of the PEEK tubing connecting the microfluidic chip with the MS, were kept short to minimise the dead volume of the set-up. In this way, the dead volume of the circuitry between fibre exit and mass spectrometer was kept below $10 \mu \mathrm{L}$. A continuous flow rate of $\varphi_{\text {tot }}=100 \mu \mathrm{L} \mathrm{h}^{-1}=27.7 \mathrm{~nL} \mathrm{~s}^{-1}$, was established using a syringe pump. The flow rate was continuously monitored with an inline microflow meter (Sensirion model SLG1430-150) placed just before the mass spectrometer. The total sample volume flow through the fibre consists of a portion flowing through the illuminated region in the core, $\varphi_{\text {core }}$, and of a portion flowing through the dark cladding holes, $\varphi_{\text {cladd }}$. By application of Hagen-Poiseuille's law for laminar flow in a parallel circuit of tubes we find $\varphi_{\text {cladd }}=5.6 \varphi_{\text {core }}$ for the fibre used. This gave rise to a flow velocity of $1.25 \mathrm{~cm} \mathrm{~s}^{-1}$ through the fibre core and hence to a sample transit time through the core $\tau_{\text {trans }}$ of $\sim 12$ seconds. This, combined with the dead volume of the rest of the system gives and overall dead time of $\sim 6 \mathrm{~min}$. However, the time between sample introduction and observation of a stable mass spectrum was found to be in the order of $15 \mathrm{~min}$. This is likely due to the intrinsic dead volume of the HRMS itself and the time needed for the spray to stabilise.

\section{Irradiation}

The photochemical conversion rate depends both on external factors as well as on intrinsic parameters relating to the molecule itself. Molecule-intrinsic parameters are characterised by the molar extinction coefficient $\varepsilon$, and the quantum yield $\Phi$, i.e. the fraction of absorbed photons that lead to the desired reaction. At an excitation wavelength of $488 \mathrm{~nm}, \varepsilon=1880 \mathrm{M}^{-1} \mathrm{~cm}^{-1}$ and $\Phi=$ $10^{-4}$ for complex $1 .^{33}$ External factors are the excitation wavelength $\lambda$ and the laser power $P$, which is directly proportional to the irradiance $I$ via $I=P / A_{\text {core }}$. The light source used here was a blue $488 \mathrm{~nm}$ laser from Toptica photonics. Prior to each individual experiment, the laser power was adjusted such that full photochemical conversion was achieved in the core, $1-C\left(\tau_{\text {trans }}\right) /$ $C_{0} \rightarrow 1$ (for details see ref. 26). This model takes also into account the length of the fibre and the fraction of light launched into the fibre core, which varied from 50 to $75 \%$ between experimental runs. Required powers $P_{0}$ were calculated to be between 8-10 $\mathrm{mW}$ for the experiments discussed below, leading to irradiances $I_{0}$ on the order of $2400-3000 \mathrm{~W} \mathrm{~cm}^{-2}$, much larger than can be achieved in conventional cuvette-based methods.

\section{Results and discussion}

The photoactive dinuclear organometallic complex $\mathbf{1},\left[\left\{\left(\eta^{6}-\right.\right.\right.$ indan) $\left.\mathrm{RuCl}_{\}_{2}}(\mu-2,3-\mathrm{dpp})\right]\left(\mathrm{PF}_{6}\right)_{2}$ (Fig. 1A), was selected for study 
by PCF-coupled-MS. The photoactivation, aquation and plasmid DNA binding properties of this compound have been reported, ${ }^{33}$ and provide a basis for the reactions investigated here. The aim of this series of experiments was to use the PCF as a microreactor to photoactivate $\mathbf{1}$ in the presence of a range of small biomolecules that are relevant to possible reactions in cells.

Upon irradiation, 1 loses an indane ligand and can bind to DNA. ${ }^{33}$ The complex can also undergo aquation in aqueous solution in the dark. Aquation can be prevented by the presence of a high concentration of $\mathrm{Cl}^{-}$ions. However, this approach is impractical, as the mass spectrometer does not tolerate high levels of salt. There were controls using conventional methods for each experiment and dark controls using both techniques. Since data from both the PCF and the conventional methods were acquired over time from aqueous solutions, account has to be taken of the possible aquation of $\mathbf{1}$ in both dark and irradiated samples.

The direct infusion (non-irradiated) controls, Fig. 2A, indicate that the fragmentation process for this molecule is different from its photodissociation and aquation pathways. Complex 1 and its products have complicated isotopic patterns; therefore all of the $\mathrm{m} / \mathrm{z}$ values reported refer to the monoisotopic peak for clarity. The main ions detected in the mass spectrum from dark solutions are the doubly-charged molecular

\section{cuvette}

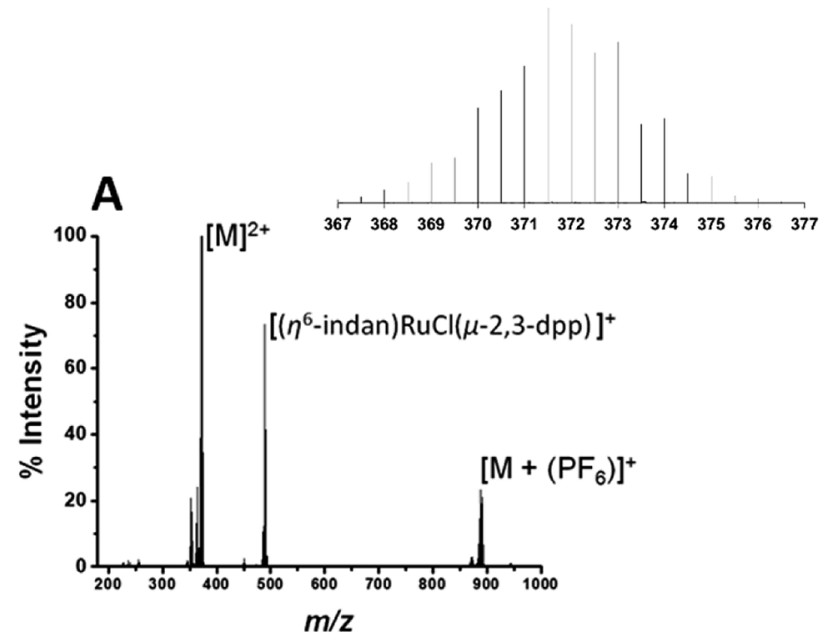

B

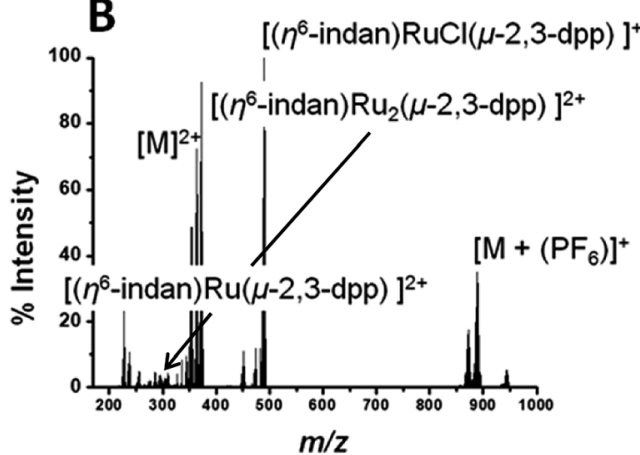

PCF-MS
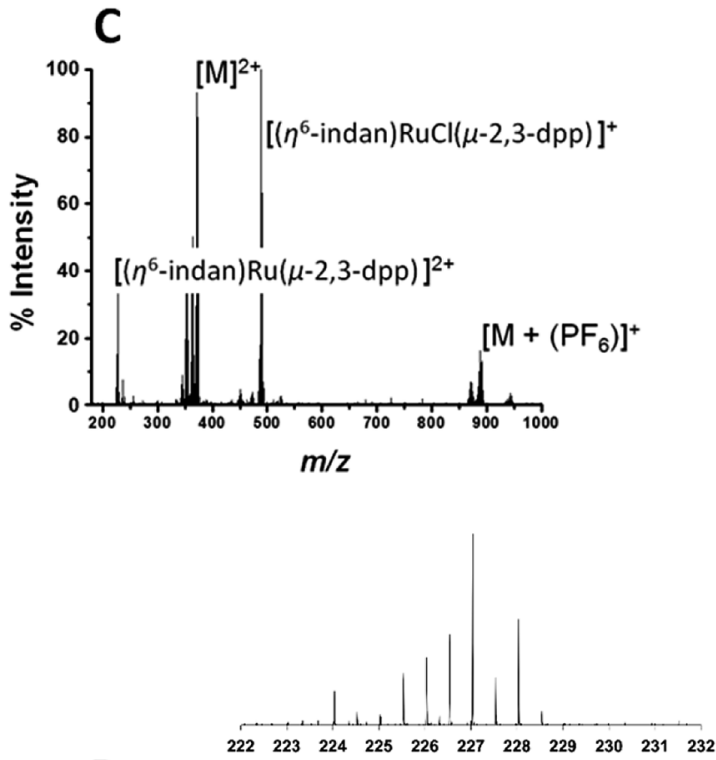

D

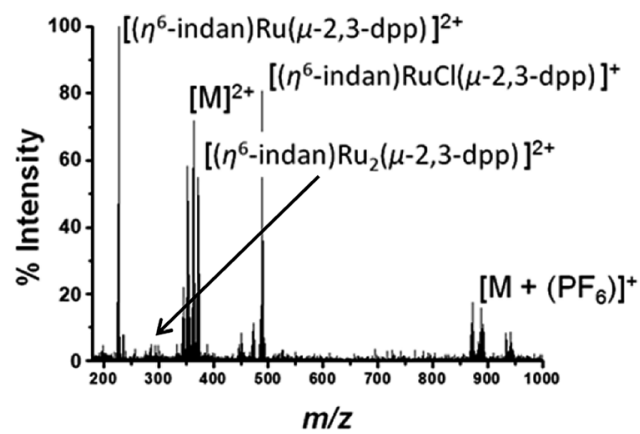

Fig. 2 (A and B) Direct infusion of solutions of 1, $250 \mu \mathrm{M}$ in DDW. Peak assignments in spectrum (A) of the solution in the dark $372.0 \mathrm{~m} / z$ [M] ${ }^{2+}$ (with inset of isotopic pattern), $888.96 \mathrm{~m} / z\left[\mathrm{M}+\left(\mathrm{PF}_{6}\right)\right]^{+}$, and at $489.01 \mathrm{~m} / z$ fragment ion $\left[\left(\eta^{6} \text {-indan)RuCl( } \mu-2,3-\mathrm{dpp}\right)\right]^{+}$. Spectrum (B) of $1250 \mu \mathrm{M}$ in DDW irradiated at $488 \mathrm{~nm}$ light $(5 \mathrm{~mW})$ for $14 \mathrm{~h}$, in a cuvette showing the appearance of a peaks at $227.04 \mathrm{~m} / \mathrm{z}$ assigned to [( $\eta^{6}$-indan)Ru(2,3$\mathrm{dpp})]^{2+}, 276.99 \mathrm{~m} / \mathrm{z}$ assignable to $\left[\left(\eta^{6}-\text { indan) } \mathrm{Ru}_{2}(\mu-2,3-\mathrm{dpp})\right]^{2+}\right.$. (C and D) PCF-MS system mass spectra of $250 \mu \mathrm{M} 1 \mathrm{in} \mathrm{DDW}:(\mathrm{C})$ solution in the dark; peaks assigned $372.0 \mathrm{~m} / \mathrm{z}$ as $[\mathrm{M}]^{2+}, 888.96 \mathrm{~m} / \mathrm{z}$ as $\left[\mathrm{M}+\left(\mathrm{PF}_{6}\right)\right]^{+}$and fragment ion at $489.01 \mathrm{~m} / \mathrm{z}\left(\left[\left(\eta^{6}-\text { indan)RuCl}(\mu-2,3-\mathrm{dpp})\right]^{+}\right) ;(\mathrm{D})\right.$ after $12 \mathrm{~s}$ of irradiation at $488 \mathrm{~nm}$ in the HC-PCF flow reactor, the new peaks at $227.04 \mathrm{~m} / z$ assigned to $\left[\left(\eta^{6} \text {-indan)Ru(2,3-dpp) }\right]^{2+}\right.$ (with inset of isotopic pattern) and at $276.99 \mathrm{~m} / \mathrm{z}$ is assigned to $\left[\left(\eta^{6}-\text { indan }\right) \mathrm{Ru}_{2}(\mu-2,3-\mathrm{dpp})\right]^{2+}$. 
ion at $372.0 \mathrm{~m} / \mathrm{z}\left([\mathrm{M}]^{2+}\right)$, a singly-charged $\mathrm{PF}_{6}$ adduct at $888.96 \mathrm{~m} /$ $z\left(\left[\mathrm{M}+\left(\mathrm{PF}_{6}\right)\right]^{+}\right)$and a singly-charged fragment ion at $489.01 \mathrm{~m} / \mathrm{z}$ $\left(\left[\left(\eta^{6} \text {-indan }\right) \operatorname{RuCl}(\mu-2,3-d p p)\right]^{+}\right)$. There are also two sets of peaks with slightly lower $m / z$ than the molecular ion at $363.51 \mathrm{~m} / z$ and $353.00 \mathrm{~m} / z$ that can be attributed to aquation of 1 and show the loss of at least one $\mathrm{Cl}^{-}$ion. In summary, the mass spectra of dark solutions of $\mathbf{1}$ show evidence for aquation and the loss of chloride ligands and fragmentation into mononuclear species. However, no loss of an indane ligand from the ruthenium was detected (Fig. 2A).

A $250 \mu \mathrm{M}$ solution of 1 in DDW was irradiated with $488 \mathrm{~nm}$ light $(5 \mathrm{~mW})$ for $14 \mathrm{~h}$ in a cuvette and the resulting spectrum is shown in Fig. 2B. The intensities of the peaks assignable to aquated $\mathbf{1}$ are higher in the spectrum of the irradiated solution that for the complex in the dark. Peaks for the species at 227.04 $m / z$ assigned to the mononuclear complex [ $\left(\eta^{6}\right.$-indan $) \operatorname{Ru}(2,3-$ $\mathrm{dpp})]^{2+}$ are more intense. The major difference in the spectra is the peak at $276.99 \mathrm{~m} / \mathrm{z}$ that is observed after irradiation and is assigned as $\left[\left(\eta^{6} \text {-indan }\right) \mathrm{Ru}_{2}(\mu-2,3-\mathrm{dpp})\right]^{2+}$. This is significant as it shows the loss of an indane ligand from $\mathbf{1}$ and provides a marker for the photodecomposition of the complex, since arene loss is not observed under dark conditions. Suggested structures for these fragments are shown in Table S1 in the ESI. $\dagger$

The experiment was then repeated in the integrated PCF-MS system. The dark spectrum in Fig. 2C shows that the only difference from the control experiment in Fig. 2A is an increase of species resulting from aquation at $363.51 \mathrm{~m} / \mathrm{z}$. This is to be expected as the compound in Fig. 2A had been in solution for a longer period of time as it was irradiated for longer. There is also a drop in overall intensities of peaks for the PCF-spectrum, which is to be expected when a reaction is transferred to the integrated system, as well as loss of intensity due to hydrolysis of the initial species. The intensity of the species $\left[\left(\eta^{6}\right.\right.$-indan $)$ $\mathrm{Ru}(2,3-\mathrm{dpp})]^{2+}(227.04 \mathrm{~m} / \mathrm{z})$ is higher for the sample injected in the dark in the PCF experiment than when directly infused in
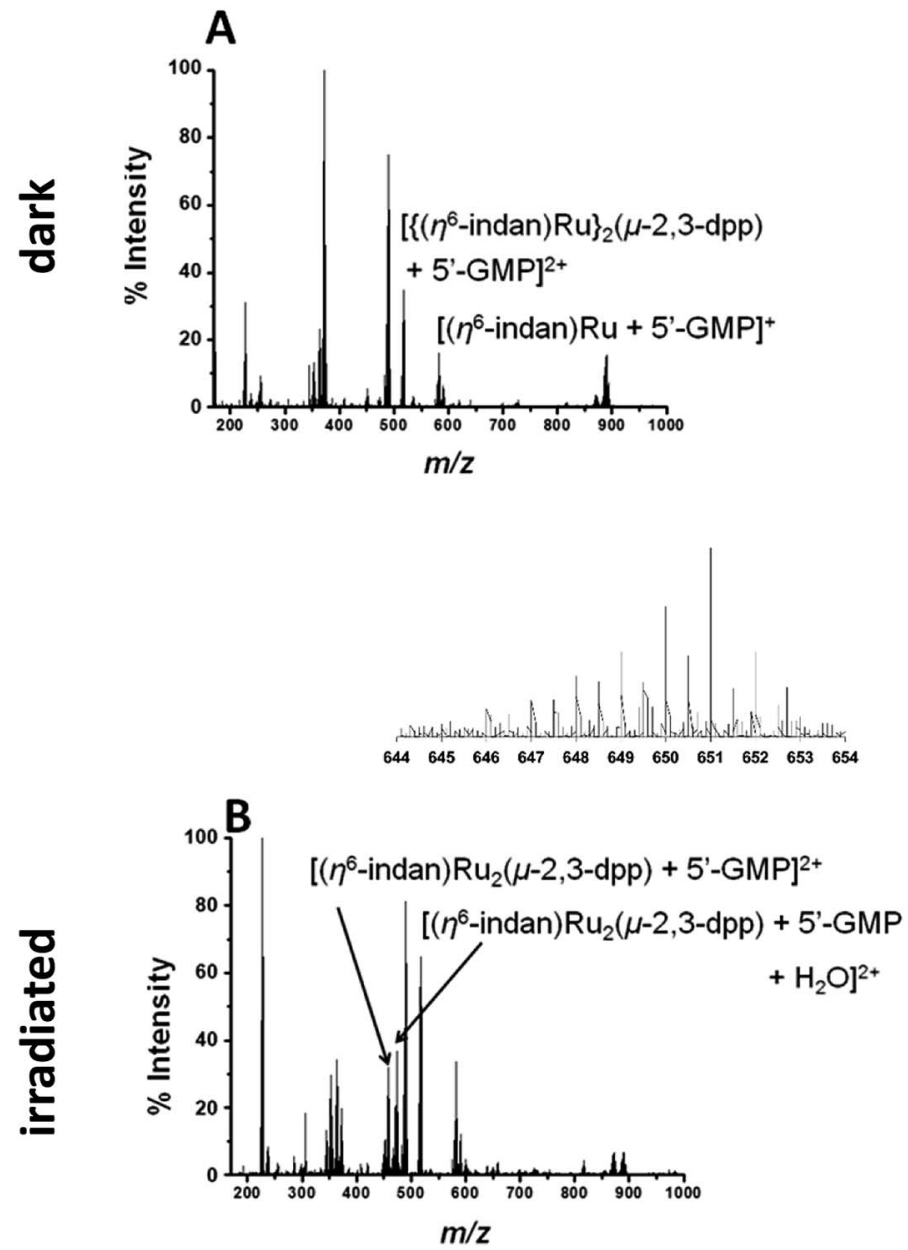
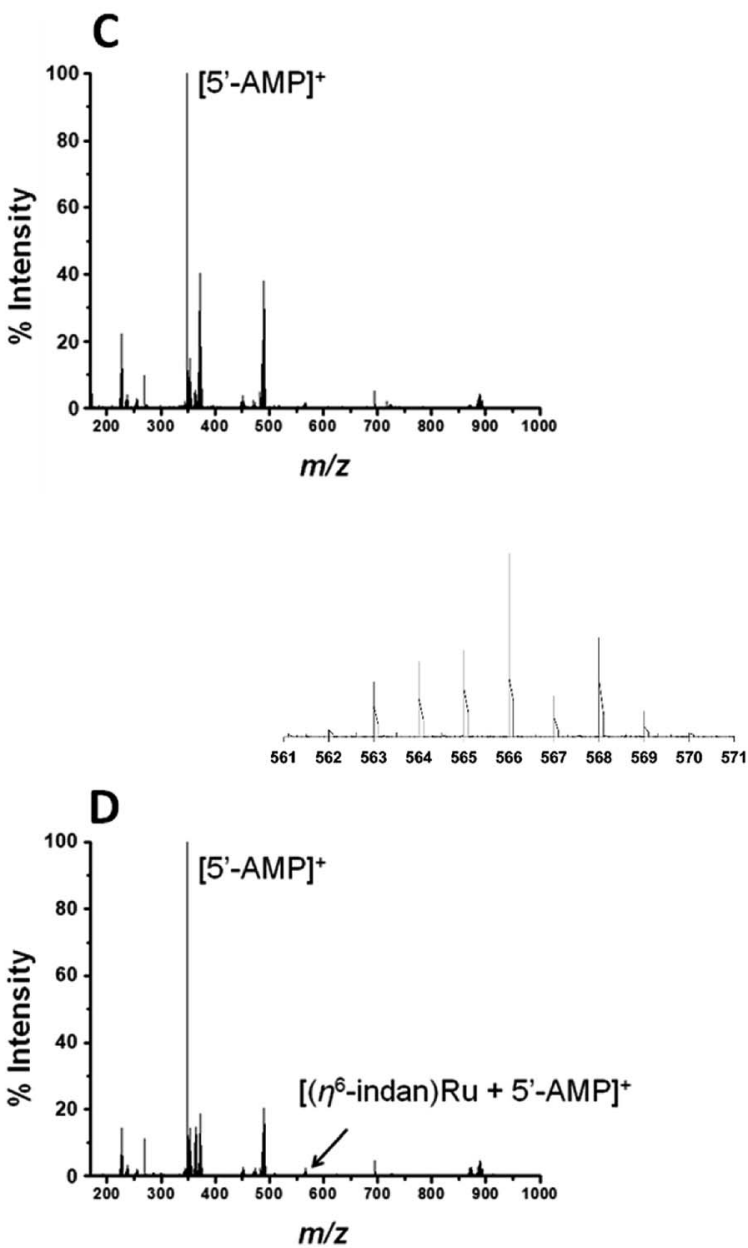

Fig. 3 (A and B) PCF-MS of $250 \mu \mathrm{M} 1$ and $500 \mu \mathrm{M} 5^{\prime}$-GMP in DDW. Spectrum (A) dark solution peak at $517.6 \mathrm{~m} / \mathrm{z}$ assigned as $\left[\left\{\left(\eta^{6} \text {-indan)Ru }\right\}_{2}(\mu-\right.\right.$ $\left.2,3-\mathrm{dpp})+5^{\prime}-\mathrm{GMP}\right]^{2+}$, the species at $582.03 \mathrm{~m} / \mathrm{z}$ is $\left[\left(\eta^{6} \text {-indan)Ru }+5^{\prime}-\mathrm{GMP}\right]^{+}\right.$, and spectrum (B) is after $12 \mathrm{~s}$ of irradiation at $488 \mathrm{~nm}$ in the $\mathrm{HC}-$ PCF flow reactor, new peaks $640.04 \mathrm{~m} / \mathrm{z}$ and $649.04 \mathrm{~m} / \mathrm{z}$ (shown in inset) are assigned as $\left[\left(\eta^{6}-\text { indan }\right) \mathrm{Ru}_{2}(\mu-2,3-\mathrm{dpp})+2\left(5^{\prime}-\mathrm{GMP}\right)\right]^{2+}$ and $\left[\left(\eta^{6}-\right.\right.$ indan) $\left.\mathrm{Ru}_{2}(\mu-2,3-\mathrm{dpp})+2\left(5^{\prime}-\mathrm{GMP}\right)+\mathrm{H}_{2} \mathrm{O}\right]^{2+}$, respectively. (C and D) PCF-MS of $250 \mu \mathrm{M} 1$ and $500 \mu \mathrm{M} 5^{\prime}-\mathrm{AMP}$ in DDW. Spectrum (C) dark solution, a peak is detected at $348.07 \mathrm{~m} / \mathrm{z}\left(\left[5^{\prime}-\mathrm{AMP}+\mathrm{H}\right]^{+}\right)$, and spectrum (D) is after $12 \mathrm{~s}$ of irradiation at $488 \mathrm{~nm}$ in the HC-PCF flow reactor, the new peak at $566.04 \mathrm{~m} / \mathrm{z}$ (shown in inset) is assigned as $\left[\left(\eta^{6} \text {-indan) Ru }+\left(5^{\prime}-\mathrm{AMP}\right)\right]^{+}\right.$. 
the dark. The mass spectrum of the irradiated PCF sample in Fig. 2D displays the same species as the irradiated control in Fig. 2B, including a significant increase in the peak at $227.04 \mathrm{~m} /$ $z$, illustrating that the PCF system does not affect the course of the reaction taking place.

Metal-based anticancer drugs that are currently in the clinic are known to bind to DNA. ${ }^{34-36}$ The DNA binding properties of 1 were modelled by irradiating it in the presence of two nucleobases with the most electron-dense donor sites (5'-GMP and $5^{\prime}$ AMP). Initially two molar equivalents of $5^{\prime}$-GMP were added to an aqueous solution of 1 (500 $\mu \mathrm{M}$ nucleobase and $250 \mu \mathrm{M}$ of complex). Spectra in the dark were obtained for both PCF-MS and conventional experiments. The samples were irradiated as follows: $14 \mathrm{~h}$ at $5 \mathrm{~mW}$ in a cuvette for the conventional measurement and $12 \mathrm{~s}$ during transfer through the PCF microreactor. The resulting data are summarized in Fig. 3. Once again there was close agreement between the conventional method and the PCF-MS experiment, the only differences being a drop in peak intensity for the PCF experiments and the appearance of the species at $658.6 \mathrm{~m} / \mathrm{z}$ in only the spectrum from the PCF irradiated sample.

In the dark spectrum in Fig. 3A, there is the appearance of a new peak at $517.6 \mathrm{~m} / z\left[\left\{\left(\eta^{6} \text {-indan }\right) \mathrm{Ru}\right\}_{2}(\mu-2,3-\mathrm{dpp})+5^{\prime}-\mathrm{GMP}\right]^{2+}$. This suggests that $5^{\prime}$-GMP binds to 1 in the dark, probably after aquation. This species appears to be fragmented in the mass spectrometer, giving rise to the ion at $582.03 \mathrm{~m} / \mathrm{z}$. Upon irradiation by conventional and PCF-MS methods new peaks were observed at $458.51 \mathrm{~m} / \mathrm{z}$ and $467.52 \mathrm{~m} / \mathrm{z}$ that are assigned as $\left[\left(\eta^{6}\right.\right.$ indan $\left.) \mathrm{Ru}_{2}(\mu-2,3-\mathrm{dpp})+5^{\prime}-\mathrm{GMP}\right]^{2+}$ and $\left[\left(\eta^{6}\right.\right.$-indan $) \mathrm{Ru}_{2}(\mu-2,3-$ dpp) $+5^{\prime}$-GMP $\left.+\mathrm{H}_{2} \mathrm{O}\right]^{2+}$ (see Fig. 3B). These species are indicative of post-irradiation binding due to the loss of an indan ring. This conclusion is further supported by the presence of a small peak at $640.04 \mathrm{~m} / \mathrm{z}$, corresponding to a doubly-charged species assigned as $\left[\left(\eta^{6} \text {-indan }\right) \mathrm{Ru}_{2}(\mu-2,3-\mathrm{dpp})+2\left(5^{\prime}-\mathrm{GMP}\right)\right]^{2+}$ and at
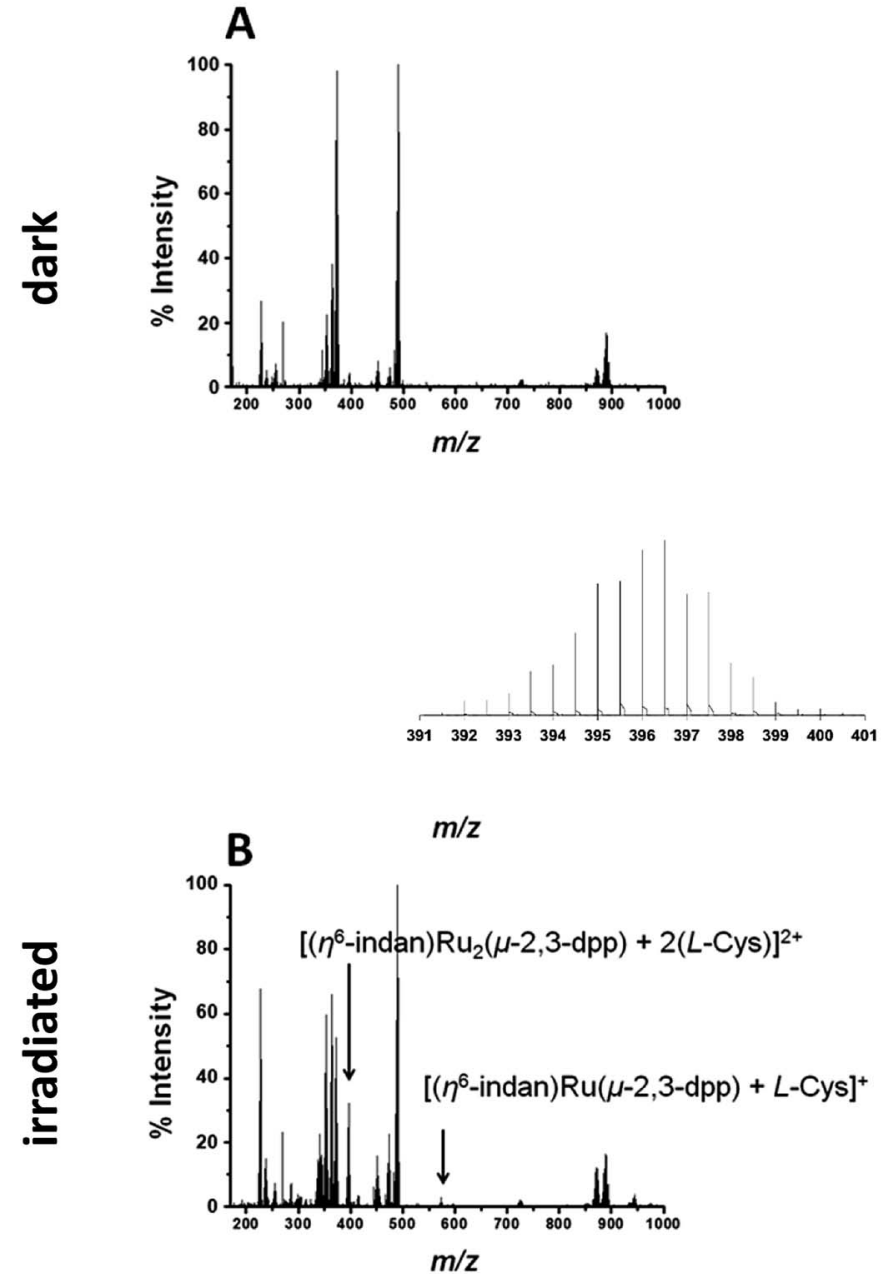
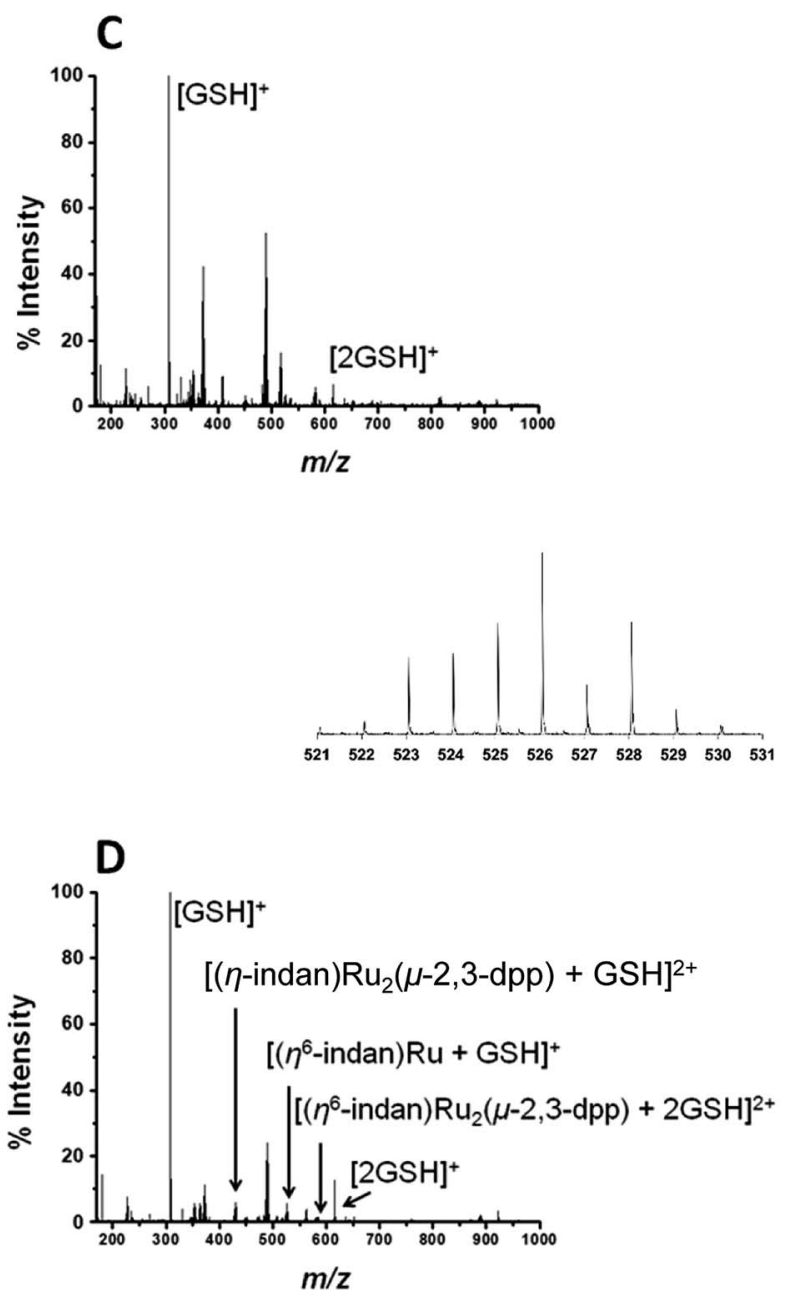

Fig. 4 (A and B) PCF-MS for the reaction of $250 \mu \mathrm{M} 1$ and $500 \mu \mathrm{ML}-\mathrm{Cys}$ in DDW. Spectrum (A) is for the solution in the dark and spectrum (B) is after $15 \mathrm{~min}$ irradiation with $488 \mathrm{~nm}$ light $(5 \mathrm{~mW})$ in a cuvette. The new peaks in spectrum (B) are assigned as $396.52 \mathrm{~m} / \mathrm{z}$ (shown in inset), $\left[\left(\eta^{6} \text {-indan) } \mathrm{Ru}_{2}(\mu-2,3-\mathrm{dpp})+2(\mathrm{~L}-\mathrm{C} \mathrm{C})\right]^{2+}\right.$ and $574.09 \mathrm{~m} / \mathrm{z},\left[\left(\eta^{6} \text {-indan) Ru( } \mu-2,3-\mathrm{dpp}\right)+(\mathrm{L}-\mathrm{Cys})\right]^{+}$. (C and D) PCF-MS of $250 \mu \mathrm{M} 1$ and $500 \mu M \mathrm{GSH}$ in DDW. Spectrum (C) is from the solution in the dark, with peaks $208.09 \mathrm{~m} / \mathrm{z}$ assigned as [GSH $+\mathrm{H}]^{+}, 615.17 \mathrm{~m} / \mathrm{z}$ as $[2 \mathrm{GSH}+\mathrm{H}]^{+}$and spectrum (D) is after $12 \mathrm{~s}$ of irradiation at $488 \mathrm{~nm}$ in the HC-PCF flow reactor, peaks at $430.52 \mathrm{~m} / \mathrm{z}, 526.06 \mathrm{~m} / \mathrm{z}$ (shown in inset) and $584.06 \mathrm{~m} / \mathrm{z}$ are assigned to $\left[\left(\eta^{6}-\text { indan }\right) \mathrm{Ru}_{2}(\mu-2,3-d p p)+\mathrm{GSH}\right]^{2+},\left[\left(\eta^{6}-\text { indan }\right) \mathrm{Ru}+\mathrm{GSH}\right]^{+}$and $\left[\left(\eta^{6}-\text { indan }\right) \mathrm{Ru}_{2}(\mu-2,3-\mathrm{dpp})+2 \mathrm{GSH}\right]^{2+}$, respectively. 
$649.04 \mathrm{~m} / z$, assigned as $\left[\left(\eta^{6}\right.\right.$-indan $) \mathrm{Ru}_{2}(\mu-2,3-\mathrm{dpp})+2\left(5^{\prime}\right.$-GMP $)+$ $\left.\mathrm{H}_{2} \mathrm{O}\right]^{2+}$. The species at $658.6 \mathrm{~m} / \mathrm{z}$ is present only in the PCF mass spectrum and is of relatively low intensity; this is assigned as $\left[\left(\eta^{6} \text {-indan }\right) \mathrm{Ru}_{2}(\mu-2,3 \text {-dpp })+2\left(5^{\prime}-\mathrm{GMP}\right)+\mathrm{H}_{2} \mathrm{O}+2 \mathrm{H}^{+}\right]^{2+}$. The binding of $5^{\prime}$-GMP that occurs after aquation of the complex also increases in the post-irradiation spectra.

Complex 1 was then irradiated in the presence of $5^{\prime}$-AMP under the same conditions as those for $5^{\prime}$-GMP $(250 \mu \mathrm{M} 1$ and $500 \mu \mathrm{M}$ nucleobase). In the dark there appeared to be no reaction between 1 and $5^{\prime}$-AMP, see Fig. 3C. After irradiation by both methods, a species appeared at $623.55 \mathrm{~m} / \mathrm{z}$; this is assigned as $\left[\left(\eta^{6} \text {-indan }\right) \mathrm{Ru}_{2}(\mu-2,3-\mathrm{dpp})+2\left(5^{\prime} \text {-AMP }\right)\right]^{2+}$ (Fig. 3B and D). The low intensity of this peak in the PCF-MS spectrum and low signal-to-noise ratio did not allow this peak to be assigned based on these data alone. However, the assignment was confirmed using the sample irradiated by conventional methods. This was also the case for the peak at $566.04 \mathrm{~m} / \mathrm{z}$, assigned as $\left[\left(\eta^{6} \text {-indan }\right) \mathrm{Ru}+\left(5^{\prime} \text {-AMP }\right)\right]^{+}$.

To study the interaction with amino acids, complex 1 was irradiated in the presence of $\mathrm{L}$-cysteine at a molar ratio of $2: 1$ (500 $\mu \mathrm{M}$ amino acid, $250 \mu \mathrm{M}$ complex). The PCF-MS sample was incubated at ambient temperature for $30 \mathrm{~min}$ in the dark, and $14 \mathrm{~h}$ for the conventional measurement. There appeared to be no reaction in the dark between $\mathbf{1}$ and L-cysteine, see Fig. 4A.

Upon irradiation by both conventional and PCF-MS methods a series of peaks appeared at $337-339 \mathrm{~m} / \mathrm{z}$. These are doubly charged ions and, from their isotopic pattern, contain more than one $\mathrm{Ru}$ atom. These species are likely to be $\left[\left(\eta^{6} \text {-indan }\right) \mathrm{Ru}_{2}(\mu-2,3-\mathrm{dpp})+(\mathrm{L}-\mathrm{Cys})\right]^{2+}, 338.49 \mathrm{~m} / \mathrm{z}$ and $\left[\mathrm{Ru}_{2}(\mu-\right.$ 2,3-dpp) $+2(\mathrm{~L}$-Cys $)]^{2+}, 339.99 \mathrm{~m} / \mathrm{z}$. However, the low intensity of the signals and overlap meant that these assignments were difficult to confirm. Two other photoproducts were also detected and are shown in Fig. 4B. These are $\left[\left(\eta^{6}-\right.\right.$ indan $) \mathrm{Ru}(\mu-$ $2,3-\mathrm{dpp})+(\mathrm{L}-\mathrm{Cys})]^{+}, 574.09 \mathrm{~m} / z$, and $\left[\left(\eta^{6}\right.\right.$-indan $) \mathrm{Ru}_{2}(\mu-2,3-\mathrm{dpp})$ +2 (L-Cys) $]^{2+}$ at $396.52 \mathrm{~m} / \mathrm{z}$.

Reactions with the tripeptide glutathione ( $\gamma$-L-Glu-L-Cys-Gly, GSH) were studied since this tripeptide often plays an important role in the cellular mechanism of resistance to metal-based drugs. ${ }^{37-39}$ Complex $1(250 \mu \mathrm{M})$ was irradiated in the presence of two molar equiv. glutathione (GSH), see Fig. $4 \mathrm{~B}$ and D, with the dark controls again incubated for the same length of time as the period of irradiation ( $30 \mathrm{~min}$ for the PCF-MS experiments and $14 \mathrm{~h}$ for the sample analysed conventionally). The dark control shows a new species at $408.56 \mathrm{~m} / \mathrm{z}$ that contains one Ru atom, is doubly charged, and appears to contain one molecule of GSH and a fragment of GSH bound with the loss of an indan group. This species was present even in the dark but its intensity decreased after irradiation. In the spectrum of the irradiated reaction more new species were observed including that at $430.52 \mathrm{~m} / z$ assigned as $\left[\left(\eta^{6}-\text {-indan }\right) \mathrm{Ru}_{2}(\mu-2,3-\mathrm{dpp})+\mathrm{GSH}\right]^{2+}$, and $526.06 \mathrm{~m} / \mathrm{z}$ as $\left[\left(\eta^{6} \text {-indan }\right) \mathrm{Ru}+\mathrm{GSH}\right]^{+}$. Species at around 580 and $584 \mathrm{~m} / \mathrm{z}$ form a cluster of peaks in the PCF-MS spectrum (Fig. 4D), but in the spectrum of the conventionally irradiated sample only the $584.06 \mathrm{~m} / z$ species, [ $\left(\eta^{6}\right.$-indan $) \mathrm{Ru}_{2}(\mu-2,3-\mathrm{dpp})+$ $2 \mathrm{GSH}]^{2+}$ is present.

\section{Conclusions}

Hollow-core photonic crystal fibre microreactors offer an integrated technique for the analysis of photochemical reactions. The combination of a low-volume microfluidic, continuous flow circuitry with high optical intensities in the HC-PCF renders the approach much less sample- and time-consuming than cuvettebased analytical approaches. This novel technique has been used here to gain new insight into reactions of potential importance to the biological mechanism of action of the dinuclear ruthenium(II) complex $\mathbf{1},\left[\left\{\left(\eta^{6}\right.\right.\right.$-indan $) \operatorname{RuCl}_{2}(\mu-2,3-$ $\mathrm{dpp})]\left(\mathrm{PF}_{6}\right)_{2}$. Complex 1 was used for exploratory PCF-MS studies as it is a positively-charged photoactivatable metal complex with potential to form novel adducts with biomolecules and so introduce a new mechanism of metallodrug action. The compound gave a high MS signal intensity when flowed through the system and unambiguous assignment of photoproducts from the complex was readily achieved. The spectra from PCFMS experiments and controls based on conventional irradiation methods showed no differences other than a small reduction in intensity of peaks for the PCF-MS spectra. All the detected species were the same by both methods. However, the time needed for sample irradiation and the total sample volume was dramatically reduced by using the PCF-MS method, from 14 hours to 12 seconds (the residence time in the HC-PCF core). Upon irradiation of $\mathbf{1}$, by both methods, there was an increase in the species at $227.04 \mathrm{~m} / \mathrm{z}$ assigned as $\left[\left(\eta^{6} \text {-indan }\right) \mathrm{Ru}(2,3-\mathrm{dpp})\right]^{2+}$, suggesting that exposure to light can result in new reaction pathways, including loss of an arene ligand.

Having established the suitability of the PCF-MS system to study the irradiation of $\mathbf{1}$, a series of experiments using a range of small molecules to act as models for larger species present within cells was carried out to gain insight into reactions that might be relevant to its biological activity. Guanine N7 is often a favoured binding site for metal-based drugs, and in the presence of the nucleotide guanosine $5^{\prime}$-monophosphate, $5^{\prime}$ GMP ${ }^{35,36} 1$ undergoes aquation and forms a mono-adduct. This is supported by the findings of Magennis et al. who reported DNA binding of 1 in the dark. ${ }^{33}$ When $\mathbf{1}$ was irradiated in the presence of $5^{\prime}$-GMP, new $5^{\prime}$-GMP adducts were detected. The binding of $5^{\prime}$-GMP that occurs following aquation of the complex also increases in the post-irradiation period.

Similarly, when photoactivated in the presence of $5^{\prime}$-AMP, adducts of $5^{\prime}$-AMP with 1 were also detected, but the peaks attributed to these are less intense than products formed by $5^{\prime}$ GMP. Magennis et al. also reported an increase in DNA binding upon irradiation. ${ }^{33}$

The reaction of $\mathbf{1}$ with L-Cys is consistent with the findings of Wang et al. who reported that $\left[\left(\eta^{6} \text {-biphenyl }\right) \mathrm{Ru}(\mathrm{en}) \mathrm{Cl}\right]^{+}$reacts slowly with L-cysteine in aqueous solution. ${ }^{5}$ Complex 1 also binds to the cysteine-containing tripeptide glutathione, which is present in cells at millimolar concentrations, as indicated by the detection of the peaks at $430.52 \mathrm{~m} / z, 526.06 \mathrm{~m} / \mathrm{z}$ and 584.06 $m / z$ assignable to $\left[\left(\eta^{6}-\text { indan }\right) \mathrm{Ru}_{2}(\mu-2,3-\mathrm{dpp})+\mathrm{GSH}\right]^{2+},\left[\left(\eta^{6}-\right.\right.$ indan $) \mathrm{Ru}+\mathrm{GSH}]^{+}$and $\left[\left(\eta^{6} \text {-indan }\right) \mathrm{Ru}_{2}(\mu-2,3-\mathrm{dpp})+2 \mathrm{GSH}\right]^{2+}$ respectively. Binding to GSH following photoactivation of 1 may 
influence its biological activity. Hence these experiments suggest that this PCF-MS system will be useful as a highthroughput method of screening for light-activated drugs, providing insight into reactions of importance to drug design and activity.

Several improvements to our current system can be envisaged: firstly, the overall time for data acquisition could be minimized by reducing the internal dead volume of the HR-MS, for instance by electrospray ionisation directly from the optofluidic interface chip. ${ }^{\mathbf{4 0 - 4 2}}$ This would allow the detection of (even) shorter-lived reaction species that are undetectable using conventional techniques. In addition, the current system could be combined with in-fibre spectroscopic methods. ${ }^{25}$ This would allow simultaneous excitation, optical detection and massspectrometry analysis of reaction products. Finally, we foresee that our approach can be combined with other lab-on-a-chip functionalities $\mathbf{4 0 , 4 3}^{\mathbf{0 , 3}}$ for sample preparation, separation and (multimodal) analysis in a straightforward fashion. In such an integrated system, laser light could be delivered by fibre-to-fibre coupling between the HC-PCF and embedded standard optical fibres, allowing easy operation without alignment of optical components.

Finally, we have used blue light in the current studies, but longer wavelength light penetrates more deeply into tissues. It would therefore be interesting to use our system to probe the metallodrugs that are optimised for excitation at longer wavelengths. An alternative strategy would be to employ a twophoton excitation process, using e.g. pulsed $800 \mathrm{~nm}$ wavelength light to achieve activation at $400 \mathrm{~nm}$. Liquid-filled HCPCFs could be used to study and optimise such nonlinear processes, as we recently demonstrated for two-photon excitation of fluorescein in a HC-PCF. ${ }^{44}$

\section{Conflict of interest}

No conflicts of interest to declare.

\section{Acknowledgements}

We thank the Koerber Foundation, ERC (Grant No. 247450), EPSRC (Grant no. EP/G006792 and MOAC studentship for RJM), Science City (ERDF/AWM) for support, Dr Abraha Habemariam for synthesis of complex 1, Dr Lijiang Song for assistance with the use of the Bruker MaXis mass spectrometer, and EC COST Action CM1105 for stimulating discussions.

\section{References}

1 I. Yoon, J. Z. Li and Y. K. Shim, Clinical Endoscopy, 2013, 46, 7-23.

2 A. Juarranz, P. Jaen, F. Sanz-Rodriguez, J. Cuevas and S. Gonzalez, Clin. Transl. Oncol., 2008, 10, 148-154.

3 T. W. Hambley, Aust. J. Chem., 2008, 61, 647-653.

4 A. Kastl, A. Wilbuer, A. L. Merkel, L. Feng, P. Di Fazio, M. Ocker and E. Meggers, Chem. Commun., 2012, 48, 18631865.
5 F. Wang, H. Chen, J. A. Parkinson, S. Murdoch Pdel and P. J. Sadler, Inorg. Chem., 2002, 41, 4509-4523.

6 S. J. Berners-Price, Angew. Chem., Int. Ed. Engl., 2011, 50, 804805.

7 S. L. H. Higgins, A. J. Tucker, B. S. J. Winkel and K. J. Brewer, Chem. Commun., 2012, 48, 67-69.

8 S. L. H. Higgins, T. A. White, B. S. J. Winkel and K. J. Brewer, Inorg. Chem., 2011, 50, 463-470.

9 L. K. McKenzie, I. V. Sazanovich, E. Baggaley, M. Bonneau, V. Guerchais, J. A. G. Williams, J. A. Weinstein and H. E. Bryant, Chem.-Eur. J., 2017, 23, 234-238.

10 H. Huang, B. Yu, P. Zhang, J. Huang, Y. Chen, G. Gasser, L. Ji and H. Chao, Angew. Chem., Int. Ed. Engl., 2015, 54, 1404914052.

11 J. Mensch, M. Noppe, J. Adriaensen, A. Melis, C. Mackie, P. Augustijns and M. E. Brewster, J. Chromatogr. B: Anal. Technol. Biomed. Life Sci., 2007, 847, 182-187.

12 S. Betanzos-Lara, L. Salassa, A. Habtemariam, O. Novakova, A. M. Pizarro, G. J. Clarkson, B. Liskova, V. Brabec and P. J. Sadler, Organometallics, 2012, 31, 3466-3479.

13 G. Ragazzon, I. Bratsos, E. Alessio, L. Salassa, A. Habtemariam, R. J. McQuitty, G. J. Clarkson and P. J. Sadler, Inorg. Chim. Acta, 2012, 393, 230-238.

14 N. J. Farrer, J. A. Woods, L. Salassa, Y. Zhao, K. S. Robinson, G. Clarkson, F. S. Mackay and P. J. Sadler, Angew. Chem., Int. Ed. Engl., 2010, 49, 8905-8908.

15 N. J. Farrer, L. Salassa and P. J. Sadler, Dalton Trans., 2009, 10690-10701, DOI: 10.1039/b917753a.

16 S. Dilruba and G. V. Kalayda, Cancer Chemother. Pharmacol., 2016, 77, 1103-1124.

17 P. St.J. Russell, Science, 2003, 299, 358-362.

18 T. A. Birks, P. J. Roberts, P. St.J. Russell, D. M. Atkin and T. J. Shepherd, Electron. Lett., 1995, 31, 1941-1943.

19 R. F. Cregan, B. J. Mangan, J. C. Knight, T. A. Birks, P. St.J. Russell, P. J. Roberts and D. C. Allan, Science, 1999, 285, 1537-1539.

20 F. Benabid, J. C. Knight, G. Antonopoulos and P. St.J. Russell, Science, 2002, 298, 399-402.

21 T. A. Birks, D. M. Bird, T. D. Hedley, J. M. Pottage and P. St.J. Russell, Opt. Express, 2004, 12, 69-74.

22 G. Antonopoulos, F. Benabid, T. A. Birks, D. M. Bird, J. C. Knight and P. St.J. Russell, Opt. Express, 2006, 14, 3000-3006.

23 D. Yin, D. W. Deamer, H. Schmidt, J. P. Barber and A. R. Hawkins, Opt. Lett., 2006, 31, 2136-2138.

24 H. Lu, M. A. Schmidt and K. F. Jensen, Lab Chip, 2001, 1, 2228.

25 J. S. Y. Chen, T. G. Euser, N. J. Farrer, P. J. Sadler, M. Scharrer and P. St.J. Russell, Chem.-Eur. J., 2010, 16, 5607-5612.

26 S. Unterkofler, Naturwissenschaftliche Fakultät, FriedrichAlexander-Universität Erlangen-Nürnberg, 2013.

27 P. St.J. Russell, J. Lightwave Technol., 2006, 24, 4729-4749.

28 A. M. Cubillas, M. Schmidt, M. Scharrer, T. G. Euser, B. J. M. Etzold, N. Taccardi, P. Wasserscheid and P. St.J. Russell, Chem.-Eur. J., 2012, 18, 1586-1590.

29 G. O. Williams, J. S. Chen, T. G. Euser, P. St.J. Russell and A. C. Jones, Lab Chip, 2012, 12, 3356-3361. 
30 A. M. Cubillas, S. Unterkofler, T. G. Euser, B. J. M. Etzold, A. C. Jones, P. J. Sadler, P. Wasserscheid and P. St.J. Russell, Chem. Soc. Rev., 2013, 42, 8629-8648.

31 S. Unterkofler, R. J. McQuitty, T. G. Euser, N. J. Farrer, P. J. Sadler and P. St.J. Russell, Opt. Lett., 2012, 37, 19521954.

32 J. M. Pratt, J. Chem. Soc., 1964, 5154-5160.

33 S. W. Magennis, A. Habtemariam, O. Novakova, J. B. Henry, S. Meier, S. Parsons, I. D. H. Oswald, V. Brabec and P. J. Sadler, Inorg. Chem., 2007, 46, 5059-5068.

34 S. E. Sherman and S. J. Lippard, Chem. Rev., 1987, 87, 11531181.

35 J. Reedijk, Eur. J. Inorg. Chem., 2009, 2009, 1303-1312.

36 J. Reedijk, Pure Appl. Chem., 2011, 83, 1709.
37 B. Köberle, M. T. Tomicic, S. Usanova and B. Kaina, Biochim. Biophys. Acta, Rev. Cancer, 2010, 1806, 172-182.

38 A.-M. Florea and D. Büsselberg, Cancers, 2011, 3, 1351.

39 T. Shoeib and B. L. Sharp, Metallomics, 2012, 4, 1308-1320.

40 R. D. Oleschuk and D. J. Harrison, TrAC, Trends Anal. Chem., 2000, 19, 379-388.

41 W.-C. Sung, H. Makamba and S.-H. Chen, Electrophoresis, 2005, 26, 1783-1791.

42 S. Koster and E. Verpoorte, Lab Chip, 2007, 7, 1394-1412.

43 M. Brivio, R. H. Fokkens, W. Verboom, D. N. Reinhoudt, N. R. Tas, M. Goedbloed and A. van den Berg, Anal. Chem., 2002, 74, 3972-3976.

44 G. O. S. Williams, T. G. Euser, J. Arlt, P. St.J. Russell and A. C. Jones, ACS Photonics, 2014, 1, 790-793. 